\title{
ASO Visual Abstract: Details and Outcomes of Distal Pancreatectomy with Celiac Axis Resection Preserving the Left Gastric Arterial Flow
}

\author{
Yosuke Inoue, $\mathrm{MD}^{1}$, Akio Saiura, $\mathrm{MD}^{1,2}$, Takafumi Sato, $\mathrm{MD}^{1}$, Atsushi Oba, $\mathrm{MD}^{1}$, Ono Yoshihiro, $\mathrm{MD}^{1}$, \\ Yoshihiro Mise, $\mathrm{MD}^{1,2}$, Hiromichi Ito, $\mathrm{MD}^{1}$, and Yu Takahashi, $\mathrm{MD}^{1}$ \\ ${ }^{1}$ Division of Hepatobiliary and Pancreatic Surgery, Cancer Institute Hospital, Japanese Foundation for Cancer Research, \\ Tokyo, Japan; ${ }^{2}$ Department of Hepatobiliary Pancreatic Surgery, Juntendo University Hospital, Tokyo, Japan
}

We detail the techniques and outcomes of DP-CAR (https://doi.org/10.1245/s10434-021-10243-3). With the following three technical tips, DP-CAR was safely performed in 55 cases with no mortality and acceptable longterm survival: left gastric arterial flow preservation, celiac axis first approach, and conservative drain management.
Publisher's Note Springer Nature remains neutral with regard to jurisdictional claims in published maps and institutional affiliations.

Supplementary Information The online version contains supplementary material available at https://doi.org/10.1245/s10434021-10303-8.

(C) Society of Surgical Oncology 2021

Published Online: 14 June 2021

Y. Inoue, MD

e-mail: yosuke.inoue@jfcr.or.jp 